\title{
CUK CONVERTER BASED REDUCTION OF COMMUTATION RIPPLES IN BLDCM
}

\author{
R. Sivakami \\ Department of Electrical and Electronics Engineering, \\ Christ Institute of Technology, Puducherry, India \\ G. Sugumar \\ Department of Electrical and Electronics Engineering, \\ Christ Institute of Technology, Puducherry, India
}

\begin{abstract}
In view of Cuk converter, a novel compensation torque swell decrease technique is proposed for brushless DC engine (BLDCM) in this paper with renewable energies as source. Yield modes (buck-help mode and lift mode) of the Cuk converter during recompense period and typical conduction period are modified by structuring a mode choice circuit, which can lessen compensation torque swell over the whole speed go. During the compensation time frame, Cuk converter works in the lift mode to step up the information voltage of three-stage connect inverter and afterward satisfy the voltage need of substitution period, with the end goal that the replacement torque swell can be diminished by keeping the non-commutated current unfaltering. So as to improve the usage pace of the converter, during the ordinary conduction time frame, Cuk converter works in the buck-help mode and the information voltage of three-stage connect inverter is directed by receiving PAM (Pulse Amplitude Modulation) technique without the inverter PWM slashing, which can lessen the voltage spike harm to the engine windings brought about by turn-on/off of MOSFET in the inverter and rearrange the program of regulation strategy further with renewable energy as its main source. The trial results confirm the accuracy of the hypothesis and the viability of the proposed methodology.
\end{abstract}

Keywords: Brushless direct current motor (BLDCM), DC bus voltage control, modified single-ended primary-inductor converter, 3-level diode clamped multilevel inverter, torque ripple

Cite this Article: R. Sivakami and G. Sugumar, Cuk Converter Based Reduction of Commutation Ripples in BLDCM, International Journal of Electrical Engineering \& Technology, 10(5), 2019, pp. 17-30.

http://iaeme.com/Home/issue/IJEET?Volume=10\&Issue=5 


\section{INTRODUCTION}

Nowadays, brushless DC motors (BLDCMs) have become a preferable choice due to several advantages such as a high power to weight ratio, a high torque to current ratio, fast response, and above all high efficiency and less maintenance. They are widely used and recommended in areas such as clean and explosive environments (where control induced sparks can cause undesirable damages), food and chemical industries, electric vehicles, and photovoltaic pumping systems. Unlike DC motors, BLDCMs have no brushes, which provides for a long lifetime. Generally, the BLDCM with trapezoidal electromotive forces (back-EMFs) is the most prevalent type, since it does not require complex control, expensive sensors, or highresolution sensors when compared to brushless AC motors. The latter need a sinusoidal current waveform while BLDCMs require a square current waveform for proper operation. The BLDCM drive control is based on a three-phase half-bridge structure that can be composed of six or four switches. Torque ripples are considered one of the main drawbacks of the BLDCM. They are generated due to several reasons such as non-ideal form of the backEMF, cogging, and reluctance torques, which have led researchers to investigate and propose several torque ripples reduction methods. For instance, the analysis of torque ripples caused by the noncommutated phase is addressed, where the PWM_ON_PWM control strategy was implemented. An auxiliary DC voltage source, connected in series with the inverters' DC bus, was employed for torque ripple reduction. A novel PWM method was established, where current spikes and current ripples, generated by the unipolar PWM control signals in the braking phases, were respectively source-illustrated and minimized. Optimal duty ratio calculation, to be applied to the incoming and outgoing phases during commutation intervals, was presented. A current optimizing control method was investigated, where the three-phase current trajectories were set according to the torque reference. Adding a DC-DC converter in with the three-phase inverter for torque ripple reduction was studied. For instance, a buck converter was the implemented topology, with power factor correction based on PID controller. Other converter topologies were also used, such as a Z-source inverter, an integrated dual output DC-DC converter, and a CUK converter. A SEPIC (Single Ended Primary Inductor Converter) DC-DC converter was implemented with a three-level neutralpoint-clamped (NPC) inverter. The output voltage of the SEPIC converter was regulated to be equal to four times the back-EMF voltage during the commutation period and was integrated using a switches selection circuit. This study was improved modified SEPIC converter to reduce the number of needed DC-DC converters with the usage of the same selection circuit. This selection circuit was eliminated to minimize the implemented components. Other works were focused on studying the torque ripple induced from the motor itself, such as, where the torque ripples caused by non-ideal back-EMF were mitigated with pulses time calculation used for switches control. Another issue regarding the BLDCM control is the current spikes. These spikes may lead to damage to the controller or the motor itself. The traditional all-turnoff current limit logic is the most used method for current limitation. However, the approach may damage the minimized DC link capacitor-based drive systems. The proposed method is based on creating a delay in the MOSFET control signals before reaching the threshold voltage (progressive reaching to the threshold voltage). This induces a smooth current flow from the source to the MOSFET's drain compared to the all-turn-off current limitation technique, where the command of the gate MOSFETs does not change from discrete states. The proposed approach allows lower input power supply use without energy flow interruptions, since the high current demand is reduced. Moreover, complicated or bulky components and sophisticated platforms are not needed for practical implementation. The effectiveness of the proposed method was analytically analyzed and validated through simulation and experimental tests 


\section{LITERATURE SURVEY}

The stator torsional vibration of permanent-magnet brushless AC/DC (BLAC/BLDC) drives with direct torque control (DTC) schemes and alternate torque-ripple compensation strategies is investigated systematically. To facilitate the analysis, a new method to measure the torsional vibration transfer function of the drive system by utilizing the cogging torque as a constant excitation source is proposed. Improved BLAC/BLDC DTC schemes, which account for the influences of nonsinusoidal back electromotive force (EMF), cogging torque, and commutation torque ripples (in the case of BLDC), are developed. Their effectiveness in minimizing low-order stator frame torsional vibration is validated and confirmed experimentally. Experimental investigation reveals that the stator torsional vibration of the prototype machine under conventional BLAC DTC operation is largely attributed to the nonsinusoidal back EMF and cogging torque while that under BLDC DTC operation is mainly caused by the cogging torque and distorted phase current during commutation interval. The torsional vibration spectra in both operating modes consist of harmonics with frequencies which are multiples of six times the fundamental electrical frequency, while their amplitudes are affected by the magnitude of exciting torque harmonics and the torsional vibration transfer function of the stator assembly.(2)

As low-resolution position sensors, a high placement accuracy of Hall-effect sensors is hard to achieve. Accordingly, a commutation angle error is generated. The commutation angle error will inevitably increase the loss of the low inductance motor and even cause serious consequence, which is the abnormal conduction of a freewheeling diode in the unexcited phase especially at high speed. In this paper, the influence of the commutation angle error on the power loss for the high-speed brushless dc motor with low inductance and nonideal back electromotive force in a magnetically suspended control moment gyro (MSCMG) is analyzed in detail. In order to achieve low steady-state loss of an MSCMG for space application, a straightforward method of self-compensation of commutation angle based on dc-link current is proposed. Both simulation and experimental results confirm the feasibility and effectiveness of the proposed method.(3)

An original analytical study concerning the torque ripple due to phase commutation on brushless DC motors is developed. The results indicate that the relative ripple is independent of current, varies with speed, and may reach $50 \%$ of the average torque. The amplitude of the torque ripple and the duration of the commutation are analyzed, showing how this affects the torque-speed curve of the drive. Simulation as well as experimental results that validate the theoretical analysis are presented.(4)

In this paper, a current optimization control method for reducing torque ripple in brushless dc drives using integral variable structure control (IVSC) is proposed. The conventional current control method will result in torque ripple if the back electromotive force (EMF) is a nonideal trapezoidal waveform. Based on back-EMF waveforms, the proposed method can optimize the reference currents in both two-phase conduction mode and commutation mode. A Luenberger full-order estimator is designed in order to estimate back-EMF waveforms. During commutation, commutation control with two-phase or three-phase switching mode is employed to reduce torque ripple by controlling the currents of noncommutated windings to trace the optimized reference current, and a three-phase inverter is switched between the two switching modes according to the current rate of change and the difference between the reference current and the actual current. Current controllers using IVSC, which exhibits broadband noise-suppressing capacity and strong robustness against external disturbances, are designed to obtain optimal phase currents, and the experimental results validate the effectiveness of the proposed method.(5) 
This paper describes an improved implementation of direct torque control (DTC) to a permanent-magnet brushless dc (BLDC) drive. The commutation torque ripple, which occurs every $60 \mathrm{deg}$ elec. in a conventional three-phase BLDC machine with two-phase $120 \mathrm{deg}$ elec. conduction, is reduced by employing a hybrid two- and three-phase switching mode during the commutation periods. It is based on the criterion of minimizing the error between the commanded torque and the estimated torque and does not require knowledge of the conduction duration of the three-phase switching mode. It adaptively adjusts the phase-current waveform to maintain constant electromagnetic torque so that commutation torque ripple, which would have resulted with conventional DTC, particularly at high rotational speeds, is effectively eliminated, as confirmed by both simulations and measurements.(6)

\section{PROPOSED SYSTEM}

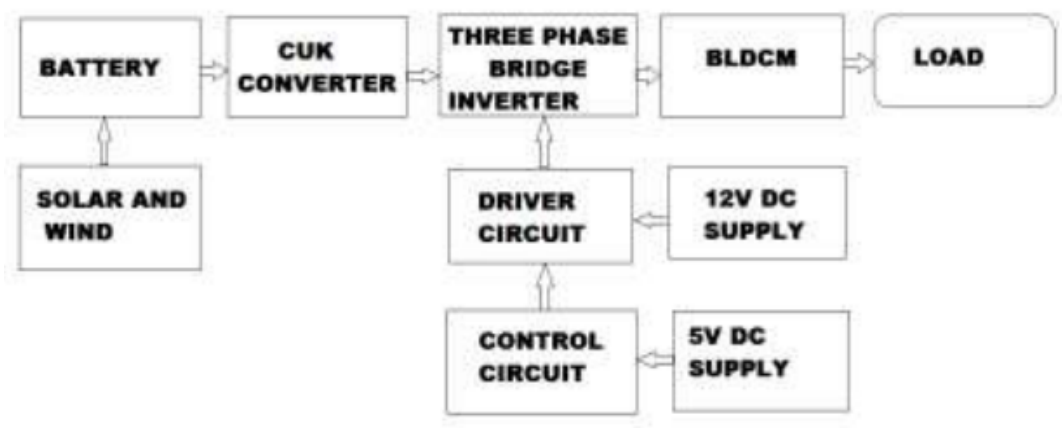

Figure 1 Proposed system block diagram

In this paper, Fig 1 a new converter topology for hybridizing the wind and solar energy sources has been proposed. In this topology, both wind and solar energy sources are incorporated together using a combination of Cuk converters, so that if one of them is unavailable, then the other source can compensate for it. Solar energy source is the input to the Cuk converter and wind energy source is the input to the converter. The average output voltage produced by the system will be the have the capability to eliminate the HF current harmonics in the wind generator. This eliminates the need of additional passive input filters in the system also step-up or step-down the input voltage sum of the inputs of these two systems. The Cuk converters during startup and overload conditions, lower input current ripple, and less electromagnetic interference (EMI) associated with the DCM topology. These converters can support step up and step down operations for each renewable energy sources. They can also support individual and simultaneous operations. All these advantages of the proposed hybrid system make it highly efficient. In Cuk converters, the average voltage across each inductor is zero whilst the average voltage across, $\mathrm{Vc}$, is as follows.

For Cuk converter $\mathrm{Vc}=\mathrm{Vo}$

The converter is operating in discontinuous capacitor voltage (DCV) mode where its input current is kept continuous. The Cuk converters operating in discontinuous current mode (DCM) can offer a number of advantages, such as inherent PFC function, very simple control, soft turn-on of the main switch, and reduced diode reversed-recovery losses. The Cuk converters offer several advantages in PFC applications, such as easy implementation of transformer isolation, inherent inrush current limitation. The output of DC-DC converters are sent to an external DC-AC inverter to supply AC power to the load. So the new proposed input side converter topology with maximum power point tracking method to meet the load and opt for a grid connected load as well as commercial loads. The implementation of new converter topology will eliminate the lower order harmonics present in the hybrid power system circuit 
A novel commutation torque ripple reduction strategy of the Cuk converter fed BLDCM is proposed. In the proposed Method, during the commutation period, the output modes of the Cuk converter are altered by the designed mode selection circuit to step up the input voltage of three-phase bridge inverter, such that the commutation torque ripple can be reduced by keeping the non commutated current steady over the entire speed range. A mode selection circuit is designed to alter the output mode of the Cuk converter. During commutation period, Cuk converter operates in the boost mode and its output voltage can meet the voltage demand of commutation period, such that the commutation torque ripple can be reduced effectively by keeping the non commutated phase current steady over the entire speed range. During the normal conduction period, the Cuk converter operates in the buck-boost mode and the input voltage of the three-phase bridge inverter is regulated by the PAM method without the inverter PWM chopping, which can reduce voltage spike damage to the motor windings caused by turn-on/off of MOSFET in the inverter, simplify the program of modulation method and improve the utilization rate of the Cuk converter.

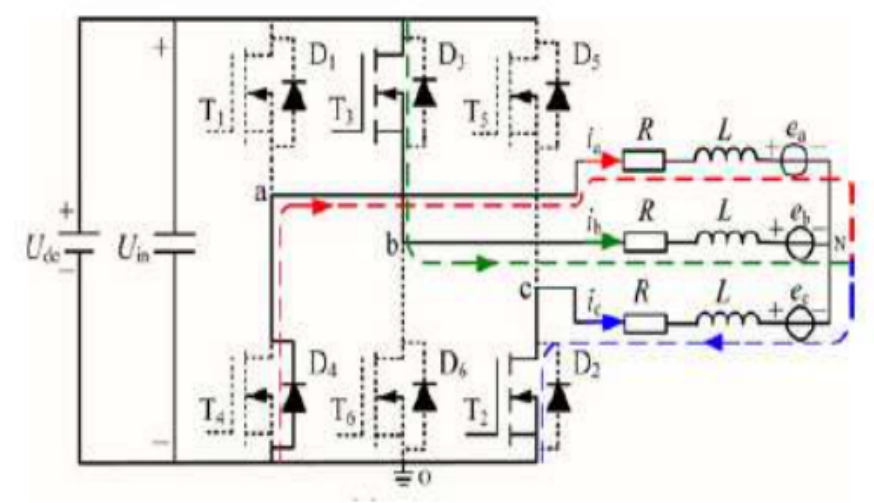

Figure 2 Equivalent circuit diagram of proposed system

The equivalent circuit of the BLDCM drive system with the assumption of three-phase symmetric stator windings is shown in Fig 2. Each phase winding can be equivalent to the resistance, inductance, and back electromotive force (EMF) in series. The Cuk converter can be used to supply power for the BLDCM as it has two different output voltages with different output modes, and the commutation torque ripple can be reduced by altering the output modes of the converter. the control unit contains the control to alter the output modes of the Cuk converter, the voltage control of the Cuk converter during the normal conduction period, the non commutated phase current stable strategy during the commutation period, and the detection module. the Cuk converter operates in two different output modes by a designed mode selection circuit and different input voltages of the three-phase bridge inverter is obtained, which provides the possibility to step up the input voltage of the inverter and then meet the voltage demand of the commutation period. PWM chopping is not required during the normal conduction period, the voltage spike damage to the motor windings caused by turn-on/off of MOSFET in the inverter is reduced, and the utilization of the Cuk converter is enhanced. The method can effectively reduce the commutation torque ripple over the entire speed range, which avoids the switch of modulation methods between high speed and low speed that may reduce the system stability, and simplifies the program of modulation method

For sensorless BLDC drive which is complex, multivariable and nonlinear, even if the plant model is well-known, there may be parameter variation problems. Fig.1 shows the circuit diagram for sensorless BLDC motor drive system. The BLDC motor is driven by a conventional three-phase inverter. DC power is supplied by rectifying the 3 phase ac supply. Control configuration shown in Fig. 1 is composed of a single-speed loop. Speed control 


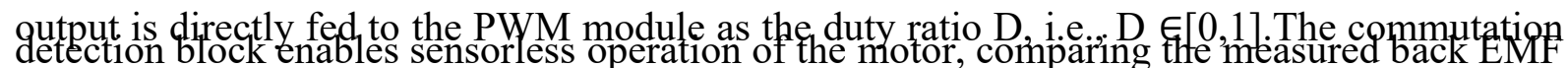
with half dc-link voltage. The PWM duty is updated six times during an electrical period and maintained constant during a mode.

The ripple contents of stator current, electromagnetic torque and rotor speed are minimized with FLC method. The advantages of Logic Controller is that it does not require any mathematical model and only based on the linguistic rules. The use of the d-q-0 reference frame for BLDCM is based on the fact that, in a three-phase Y-connected motor with nonsinusoidal air gap flux distribution, the d-q-0 transformation of the three line-to-line back EMF"cs results in the finding of the d- and q- components identical to those of three phase back EMF"s transformation.

During start-up and other severe motoring operations, the motor draws large currents, produce voltage dips, oscillatory torques and can even generate harmonics in the power system. It is therefore important to be able to model the asynchronous machine in order to predict these phenomena.

The measured phase back EMF waveforms in natural a-b-c reference frame are transformed to the d-q-0 reference frame by using the equations. where $\theta_{\mathrm{e}}=\omega_{\mathrm{e}} \mathrm{t}, \omega_{\mathrm{e}}$ is an electrical angular frequency and $\phi$ is an angular displacement between the stator current and rotor flux linkage and is generally equal to zero, and $\mathrm{C}$ is the transformation matrix of three phase to synchronously rotating $\mathrm{d}-\mathrm{q}-0$ reference frame .

In addition, if the motor is operating at high speed, a loss of transistor firing signals will result in uncontrolled regenerative braking until the motor slows to the speed where the back emf magnitude drops below the level of the dc supply voltage. Guarding against the consequences of such failures would require additional components. Above base speed, the back emf exceeds the dc supply voltage and the firing must be advanced (i.e., a phase is energized during the transition portion of the back emf where the available dc supply voltage can drive current into the motor). In the vicinity of base speed, operation is a mixture of phase advance and current regulation. At a speed only slightly greater than base speed, the current regulation becomes ineffective and all the control is accomplished by phase advance. In this work we consider only speeds at which all control is achieved through phase advance.

The phase $\mathrm{B}$ and $\mathrm{C}$ back emfs have the same shape but are delayed from phase A by $120^{\circ}$ and $240^{\circ}$, respectively. The firing of phase $\mathrm{B}$ and $\mathrm{C}$ transistors is analogous but with the appropriate delays applied. The switching frequency during pure phase advance is at the fundamental electrical frequency consistent with motor speed. Pulse width modulation is not necessary.

Transistor Q1 is fired $\theta_{\mathrm{a}}$ degrees ahead of the instant that the phase A back emf, $\mathrm{e}_{\mathrm{an}}$, reaches its positive maximum. $\theta_{\mathrm{a}}$ is called the "advance angle." Transistor Q4 is fired $\theta_{\mathrm{a}}$ degrees ahead of the instant that $e_{a n}$ reaches its most negative value. Although that can be varied from 0 to $60^{\circ}$, it is found that the limiting range is from -60 to $+120^{\circ}$. An advance angle near $30^{\circ}$, the exact value being parameter and speed dependent, results in zero average power. An advance less than this value results in regenerative braking and a greater value results in motoring operation.

\section{ANALYSIS OF COMMUTATION TORQUE RIPPLE FOR BLDCM}

The equivalent circuit of the BLDCM drive system with the assumption of three-phase symmetric stator windings. Each phase winding can be equivalent to the resistance, inductance, and back EMF in series. The three-phase terminal voltages of BLDCM are expressed as 


$$
\left\{\begin{array}{l}
u_{a}=R i_{a}+L \frac{d i a}{d t}+e_{a}+u_{N o} \\
u_{b}=R i_{b}+L \frac{d i_{b}}{d t}+e_{b}+u_{N o} \\
u_{c}=R i_{c}+L \frac{d i_{c}}{d t}+e_{c}+u_{N o}
\end{array}\right.
$$

where ua, ub and uc are the terminal voltages of the three-phase stator windings, ia, ib and ic are the phase currents, ea, eb and ec are the phase back EMFs, R is the phase resistance, $\mathrm{L}$ is the phase inductance, and $\mathrm{u}_{\mathrm{No}}$ is the neutral point voltage of the motor. The electromagnetic torque Te of BLDCM is given by

$$
T_{C}=\frac{e_{a} i_{a}+e_{b} i_{b}+e_{c} i_{c}}{\omega_{m}}
$$

where $\omega \mathrm{m}$ is the rotor mechanical angular velocity. BLDCM normally operates in the two-phase conduction mode with six steps commutation, which means only two windings are energized and the other winding is floating in the normal conduction period. Fig. 2 illustrates the ideal back-EMFs and ideal phase currents of BLDCM with ON-PWM modulation method (for example, when phase "a" is a positive phase, MOSFET T1 in upper-arm of phase " $a$ " is $\mathrm{ON}$ in the first $60^{\circ}$ electrical angles and chopping in the latter ones). Take "a+ c - " as an example, where phase "a" is a positive phase and phase "c" is a negative phase, and then ia = - ic, $\mathrm{ib}=0$, ea $=-\mathrm{ec}=\mathrm{E}$ ( $\mathrm{E}$ is denoted as phase back EMF amplitude). According to (2), the electromagnetic torque Te-noc during the normal conduction period is expressed as

$$
T_{e-n o c}=\frac{e_{a} i_{a}+e_{b} i_{b}+e_{c} i_{c}}{\omega_{m}}=\frac{2 E i_{c}}{\omega_{m}}
$$

During the commutation period, there are currents in all the three-phase stator windings due to the inductance of the stator windings, and the actual phase current cannot be a rectangular wave shown in Fig. 2. Take the commutation of the motor from " $a+c-$ " to " $b+c$ - " as an example. The back EMFs are almost constant as the duration of commutation is short, and then $\mathrm{ea}=\mathrm{eb}=-\mathrm{ec}=\mathrm{E}$. Based on the Kirchhoff's law ia $+\mathrm{ib}+\mathrm{ic}=0$, according to (2), the electromagnetic torque Te-com during the commutation period is given by

$$
T_{e-n o c}=\frac{e_{a} i_{a}+e_{b} i_{b}+e_{c} i_{c}}{\omega_{m}}=-\frac{2 E i_{c}}{\omega_{m}}
$$

According to (3) and (4), the torque ripple can be reduced by keeping the non-commutated current ic steady, which can be achieved by proper PWM method. To avoid switching modulation methods, the same modulation method is adopted during both normal conduction period and commutation period, and the PWM is applied to the non-commutated phase MOSFET during the commutation period. Take the commutation from " $\mathrm{a}+\mathrm{c}-$ " to " $\mathrm{b}+\mathrm{c}-$ " as an example, and Fig. 3 shows the currents in three-phase windings during the commutation period. As shown in Fig. 3, the outgoing phase current flows through the freewheeling diode D4 and the MOSFET T3 is ON, and the PWM is applied to the MOSFET T2. Ignoring the voltage drop of the freewheeling diode, the three-phase terminal voltages of BLDCM during the commutation period are expressed as 


$$
\left\{\begin{array}{c}
0=R i_{a}+L \frac{d i a}{d t}+E+U_{N o} \\
U_{i n}=R i_{b}+L \frac{d i_{b}}{d t}+E+U_{N o} \\
(1-d) U_{i n}=R i_{c}+L \frac{d i_{c}}{d t}-E+U_{N o}
\end{array}\right.
$$

where $d$ is the duty cycle of T2, Uin is the input voltage of three-phase bridge inverter. By adding the equations in (5) together and considering ia $+i b+i c=0$, the average neutral point voltage UNo can be derived as

$$
U_{N o}=\frac{(2-d) U_{\text {in }}-E}{3}
$$

According to the third equation in (5) and (6), the non-commutated current rate of change is derived as

$$
\frac{d i_{C}}{d t}=\frac{(1-2 d) U_{i n}+4 E-3 R i_{C}}{3 L}
$$

By setting (7) as zero to keep the non-commutated current steady, the duty cycle d can be obtained as

$$
d=0.5+\frac{4 E-3 i_{C} R}{2 U_{\text {in }}}
$$

According to (8), since $0 \leq \mathrm{d} \leq 1, \mathrm{~d}$ is the upper threshold 1 and dic $/ \mathrm{dt} \neq 0$ when $4 \mathrm{E}$ $3 \mathrm{icR} \geq$ Uin. In other word, the commutation torque ripple cannot be effectively reduced in the high speed range with the finite input voltage of three-phase bridge inverter. If the input voltage of the inverter satisfies Uin $\geq 4 \mathrm{E}$ - 3icR during the commutation period, the commutation torque ripple will be reduced effectively in the high speed range.

Phase advancing method for commutation control: inverter topology and firing scheme

The CPA method uses the common three-phase, voltage-fed inverter (VFI) topology shown in Fig. 3 shows the motor model used for simulation. The bypass diodes of the common VFI make this configuration inherently capable of regeneration. This capability is desirable in the case of controlled regenerative braking, but it also has two undesirable consequences. If a fault develops in the dc supply, the motor will feed current into the fault so long as the permanent magnets continue to rotate.

\section{DESIGN FOR SIMULATION}

Simulation experiments have been performed with parameters listed in Table I. Simulation studies were conducted and torque responses under various time ranges were observed. MATLAB version 2013a is used for simulation with wind and solar as the main input sources for the model below fig 3 . 


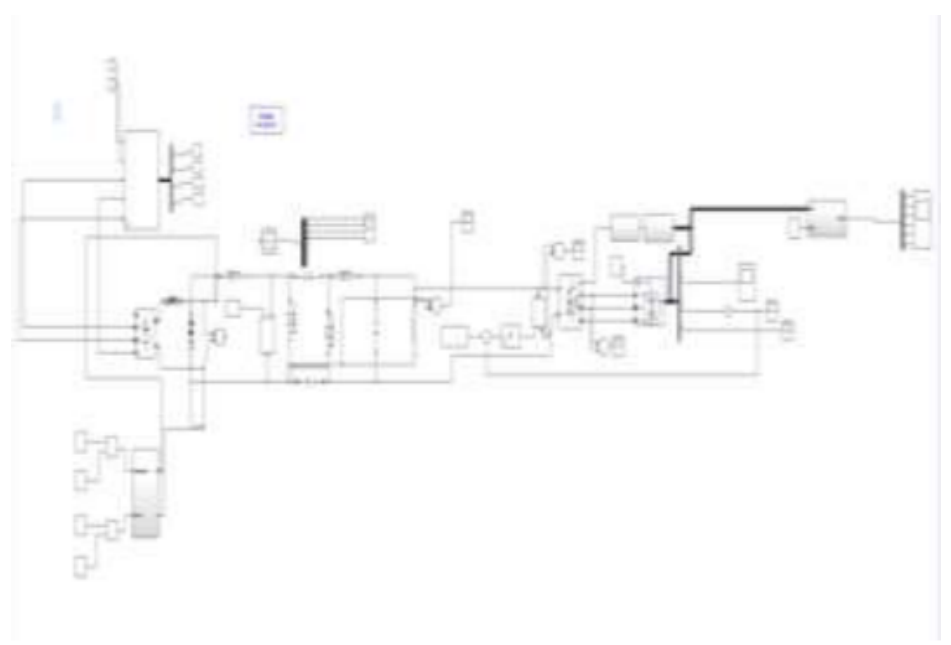

Figure 3. Proposed model

Table 1 Parameters of BLDC Motor Used in Simulation

\begin{tabular}{|l|c|}
\hline RATED POWER & $2.5 \mathrm{hp}$ \\
\hline RATED TORQUE & $1.2 \mathrm{Nm}$ \\
\hline RATED VOLTAGE & $300 \mathrm{~V}$ \\
\hline RATED CURRENT & $6 \mathrm{~A}$ \\
\hline $\begin{array}{l}\text { STATOR } \\
\text { RESISTANCE }\end{array}$ & $0.08 \Omega$ \\
\hline INDUCTANCE Ls & $1.15 \mathrm{H}$ \\
\hline MAGNETIC FLUX & $0.014 \mathrm{weber}$ \\
\hline NUMBER OF POLES & 4 \\
\hline MOMENTOF INERTIA & $0.08 \mathrm{kgm}^{2}$ \\
\hline RATED SPEED & $1500 \mathrm{rpm}^{2}$ \\
\hline
\end{tabular}

In the normal conduction period, the proportional integral (PI) controller is employed to control the current, where ip is the amplitude of the conduction phase current. In the commutation period, the duty cycle is obtained from (20) to guarantee $\mathrm{dTe} / \mathrm{dt}=0$ during the commutation process. The period switch is introduced to select the duty cycle and the modulation in normal conduction period or commutation period. In the experimental system, the torque sensor TMB307, whose measuring range is $10 \mathrm{~N} \cdot \mathrm{m}$ and resolution is less than $0.01 \mathrm{~N} \cdot \mathrm{m}$, is used to measure the output mechanical torque of BLDCM. MOSFET is manufactured by IR Corporation as IRFB4310-ZGPBF, whose switching frequency is $20 \mathrm{kHz}$. The phase current is measured using the current sensor CSM025A. The measured torque, speed and duty cycle waveforms are output by the D/A converter. The rotor type of the experimental BLDCM is surface mounted, whose parameters are shown in Table 1. 


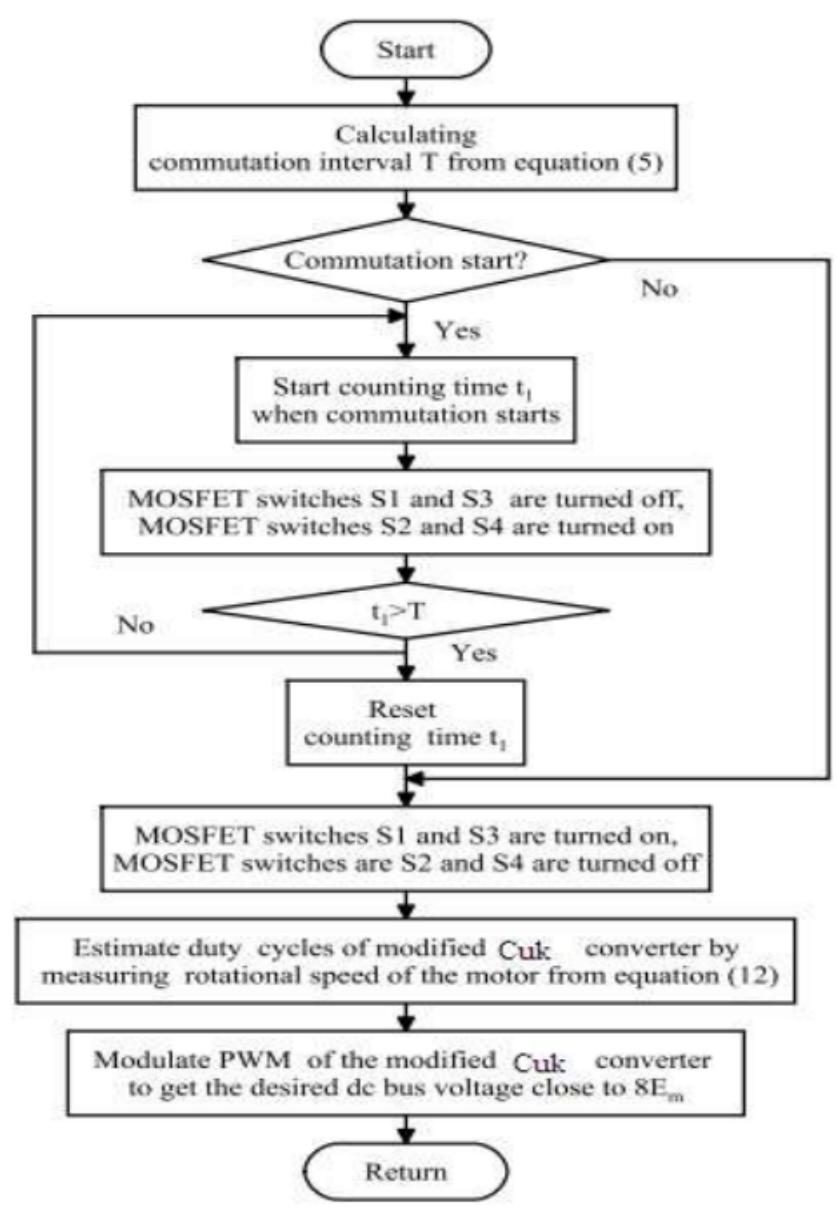

Figure 4 Execution flowchart model

In the traditional strategy, the duty cycle is calculated by (7). Except for it, the modulations and the controller in the normal conduction period are all the same as that in the proposed strategy.

\section{SIMULATION RESULTS}

From the designed model its evicted the results for the system which is given below

\section{a) Electromagnetic Torque (Nm)}

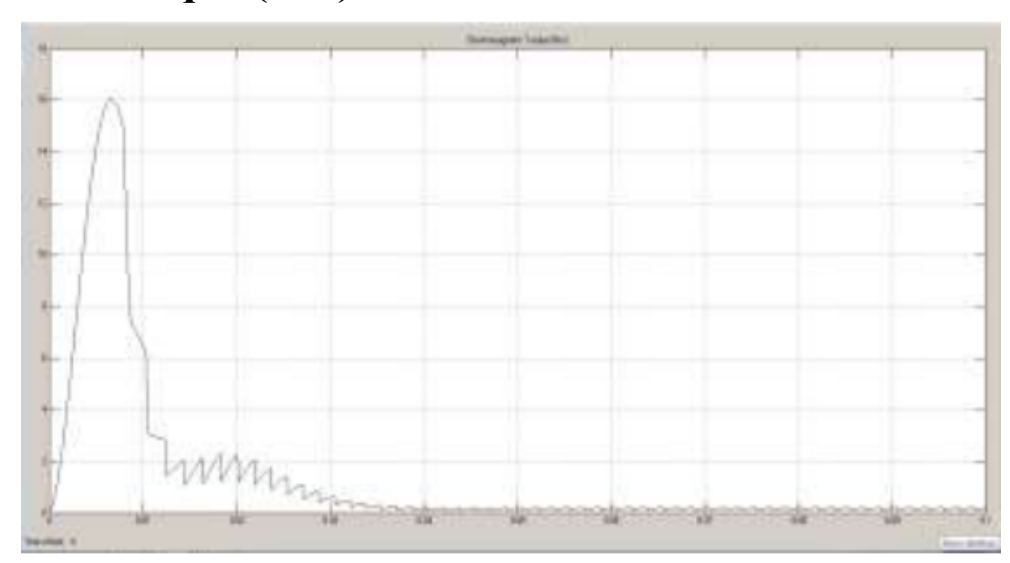

Figure 5 Electromagnetic Torque (Nm) Vs Time Interval (s) 
From the above figure it is stated the electromagnetic torque is obtained as $16 \mathrm{Nm}$ which gradually reduced to $0.025 \mathrm{Nm}$. The torque pulsations produce noise and vibration in the BLDC drive system. So elimination of noise and vibration is a main considerable problem in BLDC Motor. Two techniques are mostly used to minimize the torque ripple pulsations. To improve the motor designing factor and power electronics control schemes. Torque ripple is defined as the increases and decreases in periodic output torque. The formula for finding the torque ripple is defined as the ratio of the percentage of difference between the maximum torque ( $\mathrm{T} \max$ ) and the minimum torque ( $\mathrm{T}$ min) compared to the average torque ( $\mathrm{T}$ avg). It can be calculated that torque ripple decreases from about $45.1 \%$ to $20.2 \%$ at $1500 \mathrm{rpm}$.

\section{b) Rotor Speed (rpm)}

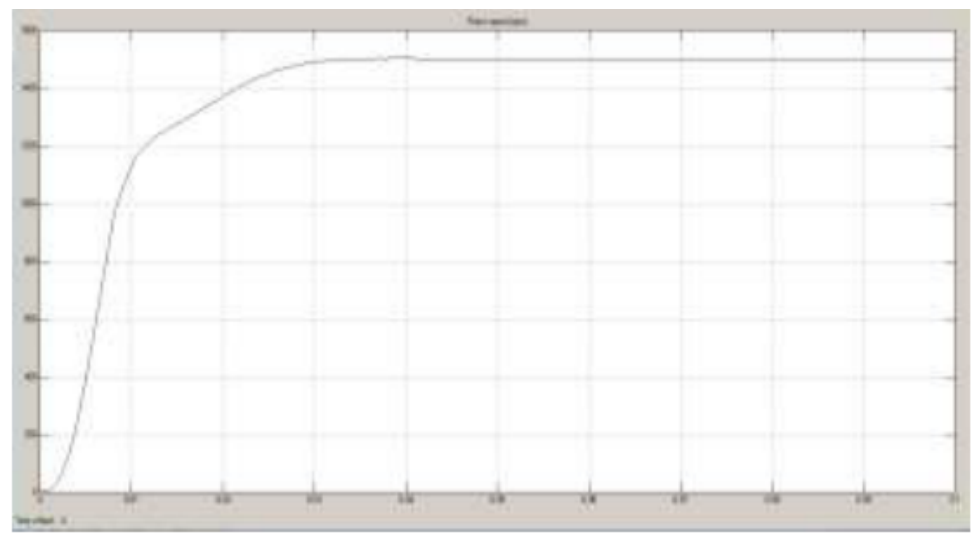

Figure 6 Rotor speed (rpm) Vs Time Interval (s)

The above figure states that the speed of the rotor of BLDC motor is increased as 1500 rpm which is the results in reduction of the commutation torque ripples. The rotor speed is obtained for $1 \mathrm{sec}$ simulation time, at the start rotor speed rises in interval from 0 to $0.04 \mathrm{sec}$ and it becomes constant for very small period in interval $(0.005,0.01)$. Then speed decreases for very small period from 0.01 to $0.03 \mathrm{sec}$, after $0.03 \mathrm{sec}$ the rotor speed becomes constant at $1500 \mathrm{rpm}$

\section{c) Stator Current ( $\left.\mathbf{i}_{\mathbf{a}}\right)$}

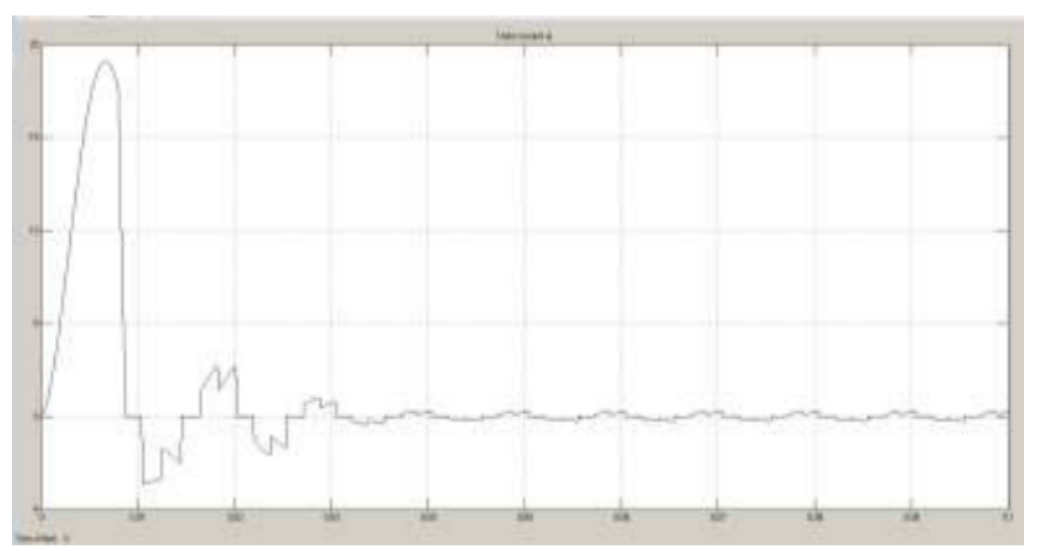

Figure 7 Stator Current (Ia) Vs Time Interval (s)

The above figure depicts the stator current of the BLDC motor, When renewable sources supply is applied to the stator winding then maximum starting stator current increases up to $19 \mathrm{amp}$ and decreases up to $-10 \mathrm{amp}$. Further it is $4 \mathrm{amp}$ in interval from 0 to 0.01 and becomes steady state stator current at lamp after 0.03 


\section{d) DC Bus Voltage}

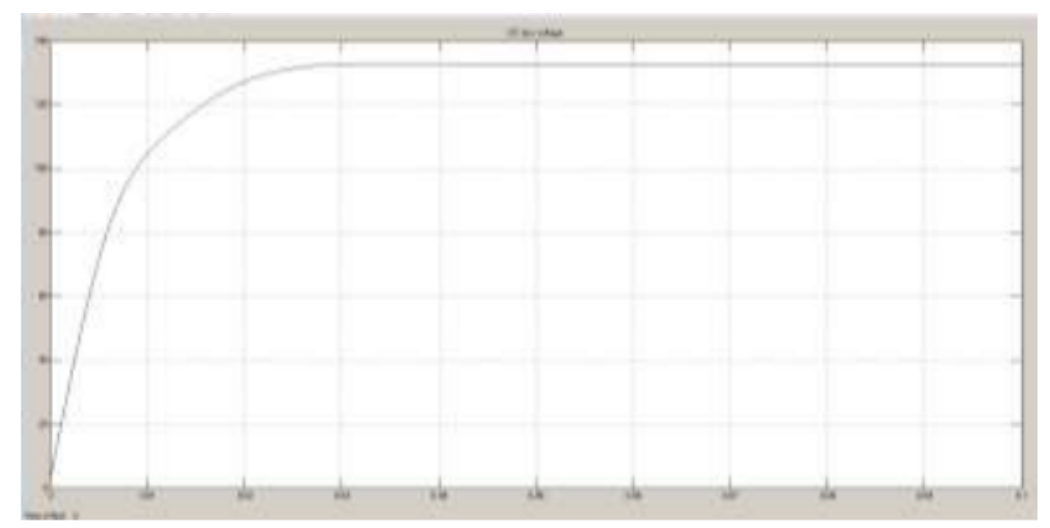

Figure 8 DC bus voltage (Vdc) Vs Time Interval (s)

For the BLDC motor to decrease the commutation torque the dc bus voltage is rated with exponential increase of $130 \mathrm{v}$ at $0.03 \mathrm{sec}$ with an interval from $0-0.03 \mathrm{~s}$. This voltage is obtained with the sources as solar and wind combine to produce the dc source.

\section{e) Line-Line Voltage}

Line voltage is the voltage measured between any two lines in a three-phase circuit.

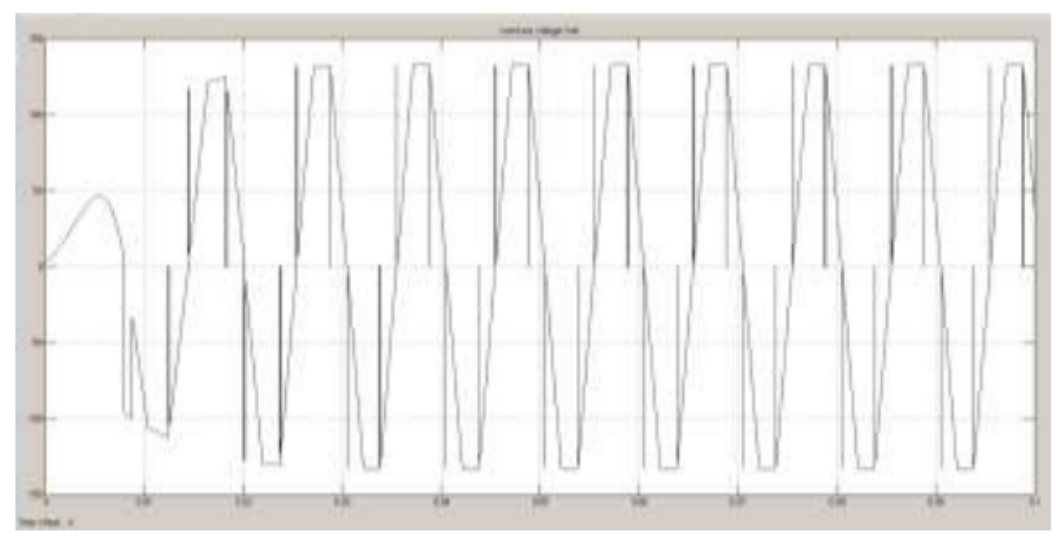

Figure 9 Line-Line Voltage (Vab) Vs Time Interval (s)

The line-line voltage $\mathrm{Vab}$ is provided in above figure which denotes that line a has its source as Solar and line $b$ has its source as Wind. The line has its voltage along the interval of $0-0.02$ as -100 to $100 \mathrm{v}$ and becomes constant at $0.02 \mathrm{~s}$ with the voltage of -200 to $200 \mathrm{v}$

\section{CONCLUSION}

A control method aimed at reducing the commutation torque ripple of the BLDC motor controller has been simulated using MATLAB. Designed system enables the simplest possible way to hold constant torque of DC brushless motor during the commutation of phases as well as during normal operation. An analytical study of torque ripple comparison due to commutation of phase currents in a brushless dc motor for $120^{\circ}$ conduction mode. The presented method may be competitive to the simple methods presented. They give us a perspective of long-term, failure-free working of tools, in which the described above drive system will be used. In the near future developed algorithm will be tested in a real drive. Obtained results confirm the effectiveness of the proposed system under various speed ranges. This result makes the motor suitable in applications such as fuel pump, robotics and industrial 
automation etc. The proposed torque ripple control method is robust, proficient and easy to implement.

\section{REFERENCES}

[1] Zhu, Z.Q.; Howe, D. Electrical Machines and Drives for Electric, Hybrid, and Fuel Cell Vehicles. Proc. IEEE 2007, 95, 746-765.

[2] Xia, C.; Jiang, G.; Chen, W.; Shi, T. Switching-Gain Adaptation Current Control for Brushless DC Motors. IEEE Trans. Ind. Electron. 2016, 63, 2044-2052.

[3] Ustun, O.; Kivanc, O.; Senol, S.; Fincan, B. On Field Weakening Performance of a Brushless Direct Current Motor with Higher Winding Inductance: Why Does Design Matter. Energies 2018, 11, 3119.

[4] Yoon, K.; Baek, S. Robust Design Optimization with Penalty Function for Electric Oil Pumps with BLDC Motors. Energies 2019, 12, 153.

[5] Priyadarshi, N.; Padmanaban, S.; Mihet-Popa, L.; Blaabjerg, F.; Azam, F. Maximum Power Point Tracking for Brushless DC Motor-Driven Photovoltaic Pumping Systems Using a Hybrid ANFIS-FLOWER Pollination Optimization Algorithm. Energies 2018, 11, 1067.

[6] Kamalapathi, K.; Priyadarshi, N.; Padmanaban, S.; Holm-Nielsen, J.; Azam, F.; Umayal, C.; Ramachandaramurthy, V. A Hybrid Moth-Flame Logic Controller Based Integrated Cuk Converter Fed Brushless DC Motor for Power Factor Correction. Electronics 2018, 7, 288.

[7] Carlson, R.; Mazenc, M.L.; Fagundes, J.C.D.S. Analysis of torque ripple due to phase commutation in brushless DC machines. IEEE Trans. Ind. Appl. 1992, 28, 632-638.

[8] Liu, Y.; Zhu, Z.Q.; Howe, D. Commutation-Torque-Ripple Minimization in DirectTorque-Controlled PM Brushless DC Drives. IEEE Trans. Ind. Appl. 2007, 43, 10121021.

[9] Jung, S.; Kim, Y.; Jae, J.; Kim, J. Commutation Control for the Low-Commutation Torque Ripple in the Position Sensorless Drive of the Low-Voltage Brushless DC Motor. IEEE Trans. Power Electron. 2014, 29, 5983-5994.

[10] Li, H.; Zheng, S.; Ren, H. Self-Correction of Commutation Point for High-Speed Sensorless BLDC Motor with Low Inductance and Nonideal Back EMF. IEEE Trans. Power Electron. 2017, 32, 642-651.

[11] Cao, Y.; Shi, T.; Li, X.; Chen, W.; Xia, C. A Commutation Torque Ripple Suppression Strategy for Brushless DC Motor Based on Diode-Assisted Buck-Boost Inverter. IEEE Trans. Power Electron. 2019, 34, 5594-5605.

[12] Tan, B.; Hua, Z.; Zhang, L.; Fang, C. A New Approach of Minimizing Commutation Torque Ripple for BLDCM. Energies 2017, 10, 1735.

[13] Jiang, G.; Xia, C.; Chen, W.; Shi, T.; Li, X.; Cao, Y. Commutation Torque Ripple Suppression Strategy for Brushless DC Motors with a Novel Noninductive Boost Front End. IEEE Trans. Power Electron. 2018, 33, 4274-4284.

[14] Shi, T.; Cao, Y.; Jiang, G.; Li, X.; Xia, C. A Torque Control Strategy for Torque Ripple Reduction of Brushless DC Motor with Nonideal Back Electromotive Force. IEEE Trans. Ind. Electron. 2017, 64, 4423-4433.

[15] Song, J.H.; Choy, I. Commutation Torque Ripple Reduction in Brushless DC Motor Drives Using a Single DC Current Sensor. IEEE Trans. Power Electron. 2004, 19, 312 319. 
[16] Shi, J.; Li, T. New Method to Eliminate Commutation Torque Ripple of Brushless DC Motor with Minimum Commutation Time. IEEE Trans. Ind. Electron. 2013, 60, 21392146.

[17] Xia, C.; Xiao, Y.; Chen, W.; Shi, T. Torque Ripple Reduction in Brushless DC Drives Based on Reference Current Optimization Using Integral Variable Structure Control. IEEE Trans. Ind. Electron. 2014, 61, 738-752.

[18] Lin, Y.; Lai, Y. Pulsewidth Modulation Technique for BLDCM Drives to Reduce Commutation Torque Ripple Without Calculation of Commutation Time. IEEE Trans. Ind. Applicat. 2011, 47, 1786-1793.

[19] Nam, K.Y.; Lee, W.T.; Lee, C.M.; Hong, J.P. Reducing torque ripple of brushless DC motor by varying input voltage. IEEE Trans. Magn. 2006, 42, 1307-1310.

[20] I. O. Lee, S. Y. Cho, and G. W. Moon, "Interleaved buck converter having low switching losses and improved step-down conversion ratio," IEEE Trans. Power Electron, vol. 27, no. 8, pp. 3664-3675, Aug. 2012. 